\title{
SOBRE A TIPOLOGIA DE ESPAÇOS FÚNEBRES CEMITERIAIS
}

\section{ON THE TYPOLOGY OF DEATH SPACES AND CEMETERIES}

\author{
Felipe Fuchs
}

\section{Resumo}

O presente artigo tem como objetivo discutir o reconhecimento e identificação dos espaços fúnebres cemiteriais. Há uma lacuna quanto à organização tipológica desses espaços, o que dificulta sua compreensão do ponto de vista da arquitetura, do paisagismo e do urbanismo. Propõe-se a adoção de termos específicos e a elaboração de um arranjo tipológico que abordem tanto aspectos relativos à composição formal, como questões vinculadas aos sentidos e relações constituídas nesses espaços. Com isso, este artigo busca a aproximação a uma leitura contemporânea do tema, aprofundando o debate sobre os espaços fúnebres e cemitérios que tem se tornado cada vez mais presente em estudos e pesquisas variados.

Palavras-chave: Espaços fúnebres. Cemitérios. Paisagens fúnebres. Tipo. Tipologia.

\section{AbStRACT}

This article aims to discuss the recognition and identification for death spaces and cemeteries. There is a gap regarding the typological organization of these spaces, which makes it difficult to understand them from the perspective of architecture, landscaping and urbanism. It is proposed the use of specific terms and the elaboration of a typological scheme that address aspects related both to formal composition, even as issues related to the meanings and relations established in these spaces. Thereby, this article seeks to approach a contemporary understanding of the theme, contributing to the debate on death spaces that has become increasingly present in many studies and researches.

Keywords: Death spaces. Cemeteries. Death landscapes. Type Typology. 
INTRODUÇÃo

A morte e as questões que lhe são relacionadas costumam ser vistas como assunto desagradável e inconveniente. Embora pareça uma condição atemporal e invariável, essa percepção se estabeleceu ao longo dos séculos XVIII e XIX, período em que se consolidou a ideia de negação da morte, conforme expressão cunhada pelo historiador Philippe Ariès (2014). Definitivamente complexa, a questão fúnebre é objeto de estudos nas mais variadas áreas de pesquisa, abrangendo uma variedade de práticas, concepções e reflexões a seu respeito. Ainda assim, ao ponderar sobre o tema de forma abrangente, é possível levantar aspectos comuns que a morte apresenta, independentemente de sua conjuntura. Nesse sentido, destacam-se, entre outros, os trabalhos de autores como Hans Belting e Edgar Morin.

Belting (2014) dedicou-se a investigar o tema da morte, dos mortos e de sua representação na arte. Para ele, a morte é uma ausência insuportável que os vivos tentam suprir de diversas maneiras. $\mathrm{O}$ autor argumenta que, na tentativa de superar essa ausência, a maior parte das culturas associa os mortos a objetos e lugares específicos onde, mediante a imagem ${ }^{1}$, ganham um corpo simbólico, imortal, ao qual ele se refere como o meio ${ }^{2}$. A partir desse processo, os vivos voltam a se relacionar e a socializar com os mortos, enquanto o corpo mortal tem seu curso definido pela sua decomposição ou metamorfose.

Concepção similar está presente nas reflexões de Morin (1997). Ao buscar um ponto comum em relação às diversas percepções e formas de elaborar a morte, o autor recorre à ideia do duplo. Morin explica que o duplo funciona como uma extensão que emana do indivíduo após sua morte, uma espécie de instância que atua no suporte do culto prestado ao morto. Ou seja, o duplo é um intermediário que acaba por substituir e simbolizar o indivíduo falecido, dando uma dimensão efetiva ao ausente.

1 Belting (2014) desenvolve em seu livro as concepções de imagem, meio e corpo. Para o autor, a imagem não é algo físico, mas uma formulação abstrata, uma referência para ajudar na compreensão de determinado tema.

2 Na perspectiva de Belting (2014), o meio se configura como algo concreto, uma espécie de suporte sobre o qual projeta-se uma imagem concebida.
Nota-se, a partir desses conceitos, que as questões material e simbólica são complementares, tendo papel fundamental para o encaminhamento da morte. Os meios ou duplos estabelecidos, qual o local de sepultamento ou o ponto de espargimento de cinzas, ganham sentido por meio da criação de vínculos essenciais ao processo de luto e à continuidade da relação estabelecida pré-morte. Como é de se esperar, a forma própria com que esses processos ocorrem muda de acordo com as especificidades de cada contexto, apresentando suas variações. Somando essa questão a fatores como os atributos arquitetônicos e paisagísticos, tem-se a composição de espaços com características distintas. A partir do seu reconhecimento, é possível refletir sobre a identificação dessas características, de modo a formar tipos ou tipologias de espaços fúnebres. Considerando o recente aumento de interesse pelo tema da morte e dos espaços fúnebres, o que se propõe é uma reflexão acerca desse reconhecimento.

Há poucos trabalhos acessíveis que tratam, efetivamente, da identificação dos espaços fúnebres. Desse modo, muitos estudos sobre o tema acabam por se basear em resoluções focadas em aspectos administrativos e normativos em detrimento dos atributos e qualidades dos espaços. Junta-se a essa problemática o fato de que alguns dos termos mais utilizados não condizem, propriamente, com a caracterização e percepção dos espaços em si, o que pode dificultar a compreensão de sua essência.

De forma ampla, pode-se refletir sobre o próprio uso da palavra cemitério, tendo em vista que seu significado é profuso e se altera ao longo do tempo. Ela costuma ser utilizada para se referir a qualquer espaço dedicado ao tema da morte, ainda que o termo carregue uma concepção específica sobre a morte, atrelada à ideia do juízo final ${ }^{3}$. Ademais, é comum usar a palavra cemitério para se referir a lugares onde se armazenam produtos fora de funcionamento, resíduos e detritos, como é o caso dos chamados cemitérios de aviões ou cemitérios nucleares. Nesse caso, ao usar o termo em associação a locais utilizados para depósito de máquinas

\footnotetext{
30 termo cemitério tem sua origem no grego, koumenterion, e no latim coemeterium, palavras usadas para designar o lugar onde se dormia, assim como o dormitório. Desse modo, o termo cemitério tem como base a ideia de repouso do corpo como um sono à espera do juízo final, concepção essencialmente cristã da morte.
} 
descontinuadas ou de itens descartados, aproxima-se os cadáveres a objetos sem mais uso, visão carregada de ideais modernistas. Nesse sentido, o termo espaço fúnebre pode ser visto como alternativa para se referir a qualquer espaço que tenha relação inerente com o tema da morte. Essa distinção não tem a pretensão de desaprovar o uso de um termo absolutamente estabelecido no idioma, mas visa, justamente, demarcar a morte como questão central na compreensão desses espaços.

Com o intuito de discutir a identificação dos tipos de espaços fúnebres, foram levantados e analisados exemplos de como esses espaços são referenciados em variados contextos da sociedade ocidental. Cada um deles determina um recorte por meio de sua conjuntura sociocultural e de critérios relacionadas ao campo de interesse da pesquisa, o que torna sua leitura indissociável de seus propósitos. De modo semelhante, é preciso pontuar que as reflexões trazidas nesse trabalho se encontram no campo de estudo dos espaços, mais precisamente dos espaços livres ${ }^{4}$.

Na sequência, tendo como base esse levantamento, o desafio proposto foi o de refletir sobre termos e princípios capazes de auxiliar na compreensão e estudo dos espaços fúnebres tendo em vista aspectos relacionados à arquitetura, à paisagem e à cidade. Por estarem relacionados a tema tão complexo e transcendental como a morte, é importante ressaltar que o artigo busca realizar essa discussão tanto no âmbito formal, como simbólico, tendo como essência refletir sobre as associações e sentidos atribuídos a esses ambientes. Com isso, espera-se contribuir para ampliar a compreensão e percepção acerca do assunto, subsidiando trabalhos que busquem seguir uma perspectiva investigativa e crítica.

\section{Levantamento e Análise de Categorizações Existentes}

Tendo como objetivo principal fins regulatórios, a classificação dos cemitérios costuma ter como base alguns fatores que podem ser considerados mais pragmáticos. Entre os mais comuns, destacam-

\footnotetext{
4 Como descreve Miranda Magnoli (2006, p. 179), "(...) o espaço livre é todo espaço não ocupado por um volume edificado (espaço-solo, espaço-água, espaço-luz ao redor das edificações a que as pessoas têm acesso)".
}

se a associação a um grupo religioso (católico, protestante, muçulmano, judaico etc.) ou a um espaço laico; o modo de administração (público, privado, concessionado); as formas de arranjo dos corpos (horizontal, vertical, misto) ou, ainda, as características dos sepultamentos. Nota-se que, enquanto as primeiras priorizam a indicação da direção e gestão dos locais, as últimas se dedicam às características físicas dos locais, sendo bastante comum sua prescrição em resoluções e regulações normativas.

Um exemplo é a Resolución 5194 de 2010, elaborada pelo Ministério de la Protección Social (COLÔMBIA, 2010). Nesse caso, tendo como critério as características de sepultamento e construções tumulares, os cemitérios são categorizados em cementerio de bovedas, cementerio de sepultura o tumba, cementerio de bovedas y sepulturas o tumbas, cementerios em altura e jardines cementerios. Essa forma de ordenação costuma ser elaborada por órgãos oficiais para regular a gestão e a prestação de serviços fúnebres como inumação, exumação e cremação.

No contexto brasileiro, para fins de regulação do licenciamento ambiental requerido para áreas de cemitérios, foi elaborada a Resolução $n^{\circ} 335$ pelo Conselho Nacional do Meio Ambiente (CONAMA), que dispõe o seguinte:

Para efeito desta Resolução serão adotadas as seguintes definições:

I - cemitério: área destinada a sepultamentos;

a) cemitério horizontal: é aquele localizado em área descoberta compreendendo os tradicionais e o do tipo parque ou jardim;

b) cemitério parque ou jardim: é aquele predominantemente recoberto por jardins, isento de construções tumulares, e no qual as sepulturas são identificadas por uma lápide, ao nível do chão, e de pequenas dimensões;

c) cemitério vertical: é um edifício de um ou mais pavimentos dotados de compartimentos destinados a sepultamentos; e 
d) cemitérios de animais: destinados a sepultamentos de animais (CONAMA, 2003, p. 98).

Em resumo, a Resolução n 335 apresenta os tipos de cemitério organizados em horizontal (que inclui as categorias tradicional e parque ou jardim), vertical, e cemitérios de animais. De forma similar, o trabalho de Ana Paula Silva Campos (2007), realizado na área da Saúde Pública, apresenta quatro tipos de espaços fúnebres: cemitério tradicional, cemitério parque ou jardim, cemitério vertical e crematórios. Em ambos os casos, nota-se a adoção de uma ordenação simples, em que as categorias têm como base uma ação regulatória sem maiores aprofundamentos a respeito de qualidades e especificidades dos espaços em si.

Seguindo por outra direção, pode-se citar o trabalho idealizado pelo Plante \& Cité, um centro de pesquisa francês dedicado aos espaços verdes e à natureza na cidade. Coordenado por Sandrine Larramendy (2017), esse estudo foca na compreensão das paisagens, usos e práticas de manutenção de cemitérios para identificar e promover iniciativas de reabilitação ecológica e paisagística. Nesse caso, a categorização se dedica a uma análise da composição dos elementos naturais do espaço, principalmente a vegetação. Assim, os cemitérios são organizados em sete categorias: (1) cemitério paisagístico5, (2) cemitério gramado e arborizado, (3) cemitério arborizado, (4) cemitério gramado, (5) cemitério em processo de vegetalização, (6) cemitério misto (parte mineral e parte vegetal) e (7) cemitério mineral.

Uma outra forma de abordagem pode ser encontrada no trabaIho idealizado pela Comissão de Propriedade Cultural de Quebec - CBCQ (2004). Coordenado pela pesquisadora Lorraine Guay, o estudo da CBCQ teve como intuito dar suporte a medidas de proteção do patrimônio funerário de Québec. O trabalho apresenta a transformação dos espaços fúnebres de forma histórico-cronológica no contexto ocidental cristão-judaico6. Foram levantados os meios e lugares de destinação dos mortos desde os primórdios do cristianismo até a atualidade, identificando quatro tipos de cemitério

5 No idioma francês, os termos cimetière paysager e cimetière végétalisé são mais usados na Europa, enquanto o termo cimetière-jardin é mais usado na américa francófona.

6 O trabalho realizado pela CBCQ tem como base os estudos sobre a morte no ocidente realizados por autores destacados como Philippe Ariès e Michel Vovelle. cristãos: (1) primitivo, (2) medieval, (3) romântico e (4) contemporâneo. Nesse caso, como os termos indicam, o objetivo do estudo foi buscar a compreensão dos espaços fúnebres a partir de contextos temporais e socioculturais, optando-se por uma abordagem baseada na periodização histórica.

Ainda no âmbito da documentação histórica, é possível citar o trabalho de Kenneth Jackson (1989). O autor estadunidense indica oito tipos de cemitérios: (1) potter's field, (2) church graveyard, (3) family burial plots, (4) country cemetery, (5) elite garden cemetery, (6) ordinary urban cemetery, (7) veterans cemetery e (8) memorial park. Nesse caso, percebe-se que o autor propõe um sistema bastante vinculado ao contexto estadunidense. Parte dos tipos sugeridos apenas ganha sentido tendo em vista as especificidades locais, como uma maior propensão à questão da ascendência, indicada pela presença da categoria de cemitério familiar, ou, ainda, identifica-se a presença de um sentimento patriótico militar, marcada pela categoria de cemitérios de veteranos militares.

Ainda em relação às categorias sugeridas por Jackson, vale o destaque para a questão de mudança de sentidos que pode ocorrer na tradução entre idiomas. Isso ocorre, por exemplo, na adoção da palavra cemitério para abranger termos do inglês como burial plot, graveyard (por vezes churchyard) e cemetery. Ao abarcar todos esses termos como se fossem sinônimo uniforme, perde-se as diferenças e nuances presentes no sentido e compreensão dos termos anteriores. Da mesma forma, destaca-se que a expressão Memorial Park carrega um sentido próprio no inglês, sendo também usada como sinônimo de cemitério ou espaço fúnebre. Desse modo, a opção por manter os termos em seu idioma original busca acentuar esse tipo de discussão, evitando traduções imediatas que podem alterar a compressão e o significado de alguns termos.

Em sua exposição a respeito dos tipos de cemitérios, o arquiteto português José Manuel Simões Ferreira (2005) segue uma linha de pensamento similar, mantendo algumas categorias em seu idioma de origem. Essa opção não implica em diminuir a importância de buscar termos no idioma do autor, mas, assim como colocado anteriormente, indica a preocupação em pontuar aspectos fundamentais presentes no conceito original. 
Adotando uma abordagem focada na teoria da arquitetura, o autor português elaborou uma pesquisa bastante minuciosa e elaborada sobre o tema. Para Simões Ferreira, é possível falar em 5 (cinco) tipos de cemitério: (1) cemitério-museu, (2) cemitério-jardim, (3) lawn green cemetery, (4) parkfriedhof ou cemitério-parque e (5) waldfriedhof ou cemitério-floresta. Em seu trabalho, o arquiteto apresenta a descrição de cada um desses tipos, investigando suas origens históricas, características e atributos formais. Ainda, Simões Ferreira especula sobre a consideração de uma outra categoria, decorrente dos estudos de Robert Auzelle (1965). No entanto, o arquiteto português opta por deixá-la de fora, argumentando que essa $6^{a}$ categoria seria uma espécie de colagem de alguns tipos pontuados anteriormente.

A conceituação de Simões Ferreira é a que mais se aprofunda na discussão conceitual, espacial e tipológica dos locais em questão. Destaca-se a diferenciação estabelecida entre as categorias de cemitério-jardim e cemitério-parque. Invariavelmente, os termos cemitério-jardim e cemitério-parque são tratados como sinônimos no contexto brasileiro, assim como em outros países latino-americanos. Portanto, pontuar essa diferença é fundamental para se aprofundar em critérios espaço-simbólicos e expandir as noções de jardim e parque para além da sua simples associação a espaços verdes.

Desse modo, o trabalho de Simões Ferreira preenche lacunas importantes no campo de estudo dos espaços fúnebres. No entanto, tendo como foco a teoria da arquitetura, chama atenção o fato de que Simões Ferreira opta por se dedicar aos tipos que se "estabilizaram" e que, para o autor, têm sido mais reproduzidos. Desse modo:

“(...) exclui-se destas considerações o tipo de cemitério em imóveis com vários andares, pois que, embora tenha proliferado por vários quadrantes geográficos durante uns tempos, parece não ter pegado, não se tendo tornado modélico. (...) Também não se vai perder tempo de maior com as propostas extravagantes de cemitérios inspiradas nos parques subterrâneos de automóveis, nem com as mnemotecas de armazenamento informático dos mortos, ou as que preconizam a miniaturização dos falecidos para o tamanho de selos e seu colecionamento em álbuns (...)" (SIMÕES FERREIRA, 2005, p. 23).

Para o arquiteto português, esses tipos de espaços não se consolidaram e, portanto, não são pertinentes ao propósito de sua pesquisa. Sob influência do trabalho de Jean-Didier Urbain e Louis-Vincent Thomas, o autor português demonstra uma rejeição ao surgimento de cemitérios que têm o desenvolvimento tecnológico como base, associando-os ao tema da ficção científica.

Ainda, mudando novamente o contexto de abordagem, é possível destacar algumas particularidades na indicação de tipos de espaços fúnebres presentes no panorama alemão. A despeito da presença de trabalhos acadêmicos que tratam do tema, como a pesquisa de Marie-Louise Hornbogen (2016), há uma maior sistematização a esse respeito. Diversos sites de informação sobre cemitérios, funerais e pontos de visitação colocam os cemitérios alemães como pertencentes a quatro tipos: (1) dorffriedhof/ kirchfriedhof, (2) allequartier-friedhof, (3) parkfriedhof e (4) waldfriedhof. Essa forma de classificação pode ser encontrada em diversos canais oficiais como o portal da cidade de Berlin ${ }^{7}$ ou em sistemas de informações sobre morte, luto e sepultamento ${ }^{8}$. Nesse caso, nota-se que há uma maior consonância sobre o tema, representada pela maior facilidade de se encontrar informações correspondentes.

Ainda referente aos tipos de cemitério na Alemanha, vale destacar que o idioma germânico tem como característica a formação de alguns termos por meio da junção de palavras. Com base no significado das palavras usadas nessa composição é criado um novo termo e, consequentemente, uma nova compreensão. Um exemplo é o próprio termo alemão para cemitério, friedhof, fruto da conjunção entre as palavras frieden (paz) e hof (pátio, recinto). De forma análoga, os tipos apresentados também são decorrentes

7 O Portal Oficial da cidade de Berlim indica os tipos de cemitérios em https://www.berlin. $\mathrm{de} /$ senuvk/umwelt/stadtgruen/friedhoefe_begraebnisstaetten/de/daten_fakten/friedhofstypen/index.shtml. Acesso em 25. Set 2020.

8 Destaque para o Friedhof Guide (www. friedhofguide.de) e o Bestattungen.de (www bestattungen.de) 
desse recurso, sendo formados a partir do acréscimo de palavras como dorf (aldeia, vila), kirch (igreja), park (parque) ou wald (floresta, bosque).

Por fim, espera-se ter demonstrado, a partir das referências trazidas, como a organização de tipos de espaços fúnebres é bastante variada, podendo seguir critérios que variam de acordo com seus objetivos e contextos. Tendo como intuito discutir os sistemas de ordenação dos espaços fúnebres, o levantamento de múltiplos métodos e formas utilizadas mostra-se fundamental para que se possa avaliar diferentes compreensões e estabelecer uma base indispensável para se dedicar ao assunto.

\section{A Construção de um Diagrama Tipológico}

Como visto anteriormente, a reflexão a respeito de um sistema de identificação para os espaços fúnebres busca aprofundar a leitura desses espaços e de suas características, debatendo temas relacionados à sua conceituação e compreensão. Para tal, é possível recorrer a algumas ferramentas habituais no reconhecimento de categorias de espaço, como a noção de tipologia. No campo dos estudos da arquitetura e da cidade, o conceito de tipologia pode ser definido como o estudo dos tipos elementares que podem constituir uma regra e, assim, ser identificados em associação a outros. Portanto, a definição de um tipo tem como pressuposto a possibilidade de se vincular uma série de características e elementos por meio de analogias com o intuito de formar instâncias de similaridades. A grande questão que surge, então, é definir quais são os parâmetros para se realizar essas analogias e estabelecer os tipos.

Entre as compreensões mais adotadas do tipo, é possível destacar aquelas que têm como base a associação por aspectos físicos e materiais de um espaço ou de uma construção, ou seja, o estabelecimento de analogias por uma proximidade de sua caracterização formal. Outro modo bastante comum de uso do recurso das tipologias é a seriação pela questão funcional, determinada com base em sua utilização ou, em um termo usual da arquitetura, seu programa. Esses entendimentos se estabeleceram ao longo do século XX por meio da difusão de manuais de leitura da cidade e de seus edifícios elaborados de forma a pontuar soluções compositivas consagradas como ferramentas de projeto.

No entanto, essas formas de associação, embora sirvam a seu propósito, deixam de lado aspectos importantes da definição de um espaço ou uma construção. Assim, sugere-se que o recurso tipológico possa abranger não apenas padrões formais e programáticos, mas também, possa percorrer uma discussão sobre os sentidos dos espaços. De certa forma, esse entendimento se aproxima da noção original dos tipos, como colocada por Quatremère de Quincy (1832) ao basear essa noção na existência de uma "razão de ser" das coisas. Ainda, aproximando os conceitos colocados por Quatremère de Quincy a uma perspectiva contemporânea, é importante situar o tipo junto a uma compreensão em que os espaços se tornam um dispositivo de viabilização de relações. Desse modo, o conceito de tipologia pode ser entendido como uma ferramenta conceitual importante para a caracterização e interpretação da relação entre expectativas sociais e estrutura espacial. Nessa perspectiva, ele se assemelha a uma espécie de "instituição social, uma solução a demandas relacionais dos indivíduos" (NASCIMENTO, 2010, p. 108).

Deslocando essa discussão para o campo dos espaços fúnebres, verifica-se que os vínculos estabelecidos com esses locais envolvem temas bastante complexos e polissêmicos como luto, memória e religiosidade ${ }^{9}$. Ao se pensar sobre a identificação de tipos nesse contexto, é fundamental que o entendimento do espaço fúnebre e de seus sentidos leve em conta, além das características físicas e compositivas, seus valores simbólicos e afetivos. Portanto, o esforço em encontrar postulados para organização das tipologias de cemitério envolve variáveis que podem estar atreladas à forma de leitura dos espaços e, consequentemente, entram no campo da subjetividade.

Ao analisar alguns termos utilizados frequentemente, optou-se por não adotar definições que acabam por indicar uma origem específica em grupos particulares, sociais ou religiosos (como cemitério militar, indígena, protestante e outros), justamente por fu-

9 Para maior aprofundamento do tema, cf. FUCHS, 2019, Parte II. 
girem da proposta colocada, servindo melhor a outros propósitos. Outra forma usual de indicar os tipos de cemitérios é o uso de termos que remetem à questão temporal. Nessas circunstâncias, a utilização de adjetivos como medieval, oitocentista ou contemporâneo fornece mais informações sobre o período de surgimento e predominância dos locais do que expressa seus atributos e qualidades. Caso seja esse o intuito, é possível estabelecer uma cronologia linear histórica como ferramenta para a análise das variações de espaço fúnebre apresentadas ao longo do tempo. Adotando como base o início da Era Comum, é possível demarcar quatro grandes períodos e seus espaços fúnebres correspondentes:

\begin{tabular}{cccc}
$\begin{array}{c}\text { Início da Era } \\
\text { Comum }\end{array}$ & Século V & Século XIX & Século XX \\
\hline $\begin{array}{c}\text { Cemitério } \\
\text { cristão primitivo }\end{array}$ & $\begin{array}{c}\text { Cemitério } \\
\text { medieval }\end{array}$ & $\begin{array}{c}\text { Cemitério } \\
\text { romântico }\end{array}$ & $\begin{array}{c}\text { Cemitério } \\
\text { contemporâneo }\end{array}$
\end{tabular}

Figura 1 - Cemitérios em cronologia histórica linear. Fonte: Diagrama elaborado pelo autor com conteúdo baseado no trabalho da Comissão de Propriedade Cultural de Quebec (CBCQ, 2004)

Esse esquema, elaborado a partir do trabalho da CBCQ (2004), é baseado nos estudos sistemáticos de caráter histórico e sociológico sobre a morte ou nas chamadas "atitudes do homem perante a morte", conforme expressão célebre de Philippe Ariès. Evidentemente, esses processos influenciaram na conformação e percepção desses locais de diversas formas, atuando de modo significativo nas definições de tipologias espaciais. Dessa forma, esse esquema pode auxiliar na compreensão da mudança dos espaços fúnebres de acordo com as transformações socioculturais decorrentes dos processos históricos.

Por fim, concentrando-se em termos capazes de indicar algumas características e sentidos do espaço em si, na sequência será apresentado um diagrama esquemático de tipologias de espaço fúnebre. Esse diagrama incorpora tanto termos mais consolidados como termos propostos por este autor, de acordo com os critérios apresentados anteriormente. Desse modo, enquanto alguns termos são facilmente encontráveis em fontes como documentos oficiais, trabalhos acadêmicos ou portais de serviços cemiteriais, outros são incipientes, frutos de levantamento, pesquisa, reflexão ou tradução própria. Na sequência, pretende-se desenvolver os argumentos e propósitos por trás dessas definições.

Sendo assim, sugere-se adotar os seguintes grupos tipológicos: (1) cemitério eclesiástico, (2) cemitério-monumento, (3) cemitério -parque, (4) cemitério-jardim, (5) cemitério-bosque, (6) cemitério ambiental e (7) cemitério-edifício, dispostos conforme diagrama apresentado na sequência (Figura 2).

\section{Os TIPos}

O termo cemitério eclesiástico foi adotado para se referir aos tipos de espaços fúnebres predominantes durante o período medieval, quando a Igreja era responsável pelos enterros e pelas questões fúnebres. A opção por esse termo busca salientar essa conjuntura de forma ampla, englobando os seguintes espaços: (a) vala comum, (b) Igreja-cemitério, (c) cemitério de claustro (Campo Santo) e (d) cemitério de adro. Esses espaços podem ser encontrados separadamente ou em conjunto, apresentando variações de acordo com seu contexto específico.

Para entender as formas de relação com esses espaços, é preciso ter em vista que no período medieval a percepção da morte era distinta da atual, sendo marcada por "uma sociedade em que coabitam os vivos e os mortos, em que o cemitério se confunde com a igreja no coração da cidade" (VOVELLE, 1976, p. 126, tradução nossa). Essa familiaridade entre vivos e mortos tinha como base uma concepção coletiva do destino após a morte, dada pela compreensão da morte como uma das grandes leis da espécie. Nesse contexto, não havia a tentativa de se controlar ou de se escapar da morte, mas "aceitava-a simplesmente como justa" (ARIĖS, 2010, p. 33). Diante disso, os cemitérios eclesiásticos eram espaços onde ocorriam variadas atividades e manifestações, dando a eles conotação similar a de uma praça pública. Isso era possível justamente pela forma de relação estabelecida entre os vivos e os mortos, fundindo -os em uma comunidade que não precisava diferenciá-los do ponto de vista da ocupação espacial (REIS, 1991). 
DIAGRAMA TIPOLÓGICO DE ESPAÇOS FÚNEBRES CEMITERIAIS

(1)

CEMITÉRIO ECLESIÁSTICO

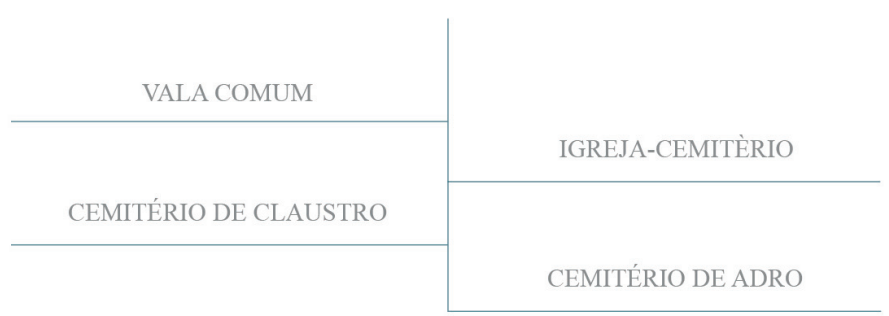

(2)

\begin{tabular}{ccc}
$\begin{array}{c}\text { CEMITÉRIO- } \\
\text { MONUMENTO }\end{array}$ & $\begin{array}{c}\text { CEMITÉRIOS } \\
\text { CIVIS }\end{array}$ \\
\hline & CEMITÉRIO-EDIFÍCIO \\
CEMITÉRIOS \\
VERDES
\end{tabular}

(3)

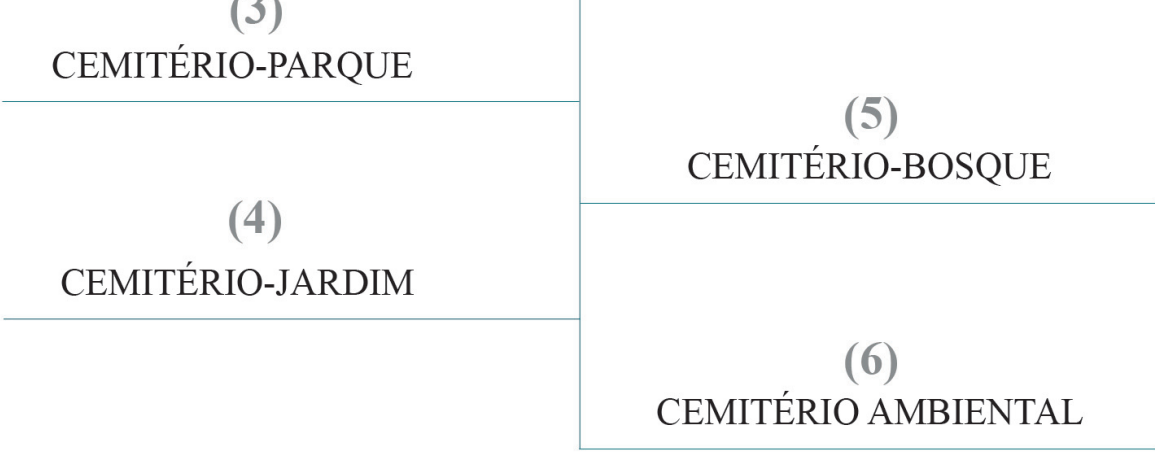

Figura 2 - Diagrama tipológico de espaços fúnebres cemiteriais. Fonte: Elaborado pelo autor. 
Nesse período, o pressuposto fundamental de ordenação dos corpos dos falecidos era o sepultamento próximo aos santos e mártires, que protegiam as sepulturas do profano e libertavam os indivíduos dos pecados cometidos em vida. Quanto mais perto aos pontos sagrados, como o altar e as relíquias, mais próxima da salvação a pessoa estaria.

A vala comum ${ }^{10}$ eram os espaços usualmente nos arredores da Igreja onde as classes mais baixas eram enterradas, estabelecendo uma distinção social dada pela distância dos santos e mártires da Igreja. A adoção do termo Igreja-cemitério indica a situação onde a própria edificação da Igreja abrigava os corpos dos mortos. Boa parte das igrejas abriga, em seu interior ou subsolo, os corpos de figuras de classes mais privilegiadas e que, portanto, recebiam maior destaque. Com o passar do tempo, outros espaços dos conjuntos eclesiásticos também foram sendo ocupados para enterros, como os claustros e os adros. O termo inglês graveyard se refere justamente a esses locais, sendo comumente usado como sinônimo de cemitério em idiomas de raiz anglo-saxã que ainda utilizam o termo churchyard de modo similar. No alemão, esse tipo são os chamados kirchfriedhof. Apesar de predominantemente saturados, esses cemitérios são parte fundamental do cenário sociocultural do período em questão, sendo que muitos deles ainda estão em funcionamento, servindo como destino de enterros nos dias atuais.

Para o segundo tipo apresentado, optou-se pelo termo cemitério-monumento. Com algumas variações tipológicas, ele pode ser chamado ainda de cemitério tradicional, cemitério monumental, cemitério urbano, cemitério oitocentista, cemitério-museu e cemitério mineral. Ele representa os espaços fúnebres marcados substancialmente pela presença de construções e elementos fúnebres expressivos. Usualmente, esses locais apresentam um traçado bem definido, composto por alamedas de circulação e quadras. As quadras, por sua vez, são divididas em lotes que delimitam o local de sepultamento, caracterizados justamente pela presença das construções e elementos fúnebres, os monumentos. Esses representam um repertório variado e rico, associando esses locais à compreen-

\footnotetext{
10 Nota-se que, nesse caso, o termo vala comum se refere ao enterro de um grupo de cadáveres conjuntamente, realizado no período medieval próximo às igrejas. No entanto, a adoção de valas comuns se faz presente também em outros momentos históricos e situações, muito mais como um expediente ímpar do que como um tipo.
}

são do espaço como um museu ou, ainda, em referência à materialidade dos monumentos elaborados em rochas minerais.

Em latim, o verbo monere, raiz etimológica de monumento, significa fazer recordar (LE GOFF, 1990). Assim, o monumento é tudo aquilo que pode evocar o passado e perpetuar a recordação. 0 historiador Fernando Catroga (2010) pontua que esse tipo de cemitério apresenta um caráter monumental manifestado por meio da expressão simbólica de seus marcos fúnebres que o levam a assumir a função de lugar de produção e reprodução da memória. Todo cemitério tem um caráter monumental, no entanto, esse cemitério tem nessa forma de expressão a sua principal marca, ocupando assim um lugar de destaque no imaginário icônico fúnebre. Essa característica é o que faz com que esse tipo de cemitério seja o que mais se aproxima do conceito de memento mori ${ }^{11}$, expressão romana que remete à noção de finitude como o destino inalienável de todos os seres vivos.

O surgimento desse tipo de cemitério representa um marco no tratamento da questão fúnebre, inaugurando o que pode ser chamado como período dos Cemitérios Civis, onde houve a transferência de responsabilidade pela questão fúnebre da Igreja para os Estados modernos por meio da secularização. A principal referência na conformação desses espaços foi o estabelecimento do Cemitério de Père-Lachaise, realizada em 1804, na cidade de Paris. Sua abertura promoveu um discurso que buscava instituir cemitérios mais afastados dos centros urbanos. A base para esse processo de escamoteamento foi uma visão sanitarista que se apoiava na teoria dos miasmas ${ }^{12}$ e no risco que a proximidade com os mortos passou a representar à saúde. Esse discurso ganhou bastante eco à época, influenciando na caracterização dos espaços fúnebres por meio de aspectos como a definição de regras de separação entre os corpos enterrados e uma maior incorporação de vegetação. Havia uma percepção de que o cenário natural tinha um impacto positivo nas

11 Traduzido do latim, significa algo como "lembre-se da morte" ou "lembre-se de que você vai morrer".

12 Doutrina que postulava que a matéria orgânica em decomposição, especialmente de origem animal, sob a influência de elementos atmosféricos como temperatura, umidade e direção dos ventos, formava vapores ou miasmas nocivos à saúde, infectando o ar que se respirava 
pessoas, contribuindo para lidar com as dores e sentimentos frente à morte.

A partir de então, foram surgindo variações de espaços fúnebres cemiteriais onde a utilização da vegetação e elementos naturais ganhou cada vez mais relevância, tornando-se peça fundamental para a conformação dos espaços. A presença de vegetação nos cemitérios tinha dois propósitos principais: atender aos princípios de salubridade vigentes e aproximar-se da ideia de natureza. Com o caminhar dos anos, o sentido dessa aproximação à natureza apresentou algumas variações, expressando formas, percepções e associações que ganharam significados divergentes de acordo com seu contexto.

A partir da compreensão de diferentes sentidos da noção de aproximação à natureza diante da morte, sugere-se que os cemitérios com maior presença de vegetação, ou cemitérios verdes, sejam reconhecidos pelos seguintes tipos: cemitério-parque, cemitériojardim, cemitério-bosque e, mais recentemente, o cemitério ecológico. Ressalta-se que o conceito de cemitério-parque é proposto aqui de forma distinta de cemitério-jardim. Acredita-se que a junção de termos seja muito mais por uma associação de espaços predominantemente verdes do que devido à sua caracterização formal ou pelos meios de relação com o espaço. Esses termos são constantemente apropriados pelo mercado imobiliário urbano que busca "agregar" valor ao produto cemitério por meio dessa associação.

Portanto, à parte do possível uso desses termos de forma comercial, sugere-se que o conceito de cemitério-parque seja usado para se referir ao espaço fúnebre organizado como um parque, ou seja, um espaço de proporção relevante, com presença marcante de vegetação e que, de alguma forma, propicia a permanência e o convívio em seus espaços.

Os parques urbanos surgiram em um contexto em que se buscava introduzir a natureza ao ambiente urbano de forma acentuada e ostensiva. Os cemitérios-parque, assim como os parques, eram marcados pelo acompanhamento da topografia natural e pela presença de elementos da paisagem natural como a terra, a água e vegetações arbórea, arbustiva e forrações. Essa caracterização se faz presente no espaço como um todo, alterando a relação com os locais de enterro. É possível haver uma variação grande dos tipos de construção fúnebre, porém, via de regra, elas costumam ser mais discretas que as do cemitério-monumento.

O Mount Auburn, em Boston, é um marco de referência para os cemitérios-parque. Conhecido nos Estados Unidos como um rural cemetery ${ }^{13}$, esse tipo de ambiente surgiu a partir da introdução de conceitos da horticultura que remetem ao estabelecimento de um aspecto bucólico ${ }^{14}$. Desse modo, a introdução desses espaços marcou a busca por criar lugares mais vegetados, em contraposição ao espaço cinzento industrial que vinha tomando conta do ambiente urbano desde a Revolução Industrial. Schuyler (1986) aponta que esses cemitérios foram os primeiros grandes espaços planejados paisagisticamente e com grande presença de vegetação nos Estados Unidos que foram abertos a visitas públicas, ou seja, ao alcance de toda população. Com isso, eles se tornaram fundamentais para o estabelecimento do próprio movimento de parques urbanos no contexto estadunidense.

Conceitualmente, pode-se dizer que a associação desse tipo de espaço fúnebre à ideia de parque é entendida sob a ótica de um retorno a uma natureza domesticada, um ambiente cuidadosamente pensado de modo a propiciar um ideal de natureza. Com o passar dos anos, a forma de se configurar esses espaços pode ter alterado, mas a essência da associação a uma forma de natureza domesticada em contraposição ao ambiente urbano construído foi mantida. Os cemitérios-parque se tornaram um dos tipos de espaço fúnebre com maior apreço, podendo ser encontrados em diversos países e regiões.

Outro tipo de cemitério verde, comumente utilizado como sinônimo de cemitério-parque, é o cemitério-jardim. Nesse caso, a presença de vegetação também é um dos principais atributos do espaço, no entanto, ela costuma ser menos ostensiva e bucó-

13 Muitas fontes se referem a esses lugares como cemitérios rurais, tradução que no português brasileiro pode escapar um pouco do sentido bucólico original. Desse modo, sugere-se adotar o termo cemitério campestre, ou ainda, indicar o cenário estadunidense como referência, tendo em vista que esse tipo se manteve bastante restrito a esse contexto.

$14 \mathrm{Em}$ pesquisa de mestrado (FUCHS, 2019) discute-se essa concepção, sugerindo o uso do termo campestre no português brasileiro, que melhor representa os ideais bucólicos e naturalistas de sua idealização. 
lica, estabelecendo uma relação maior de contemplação. No cemitério-jardim é comum que os marcos funerários sejam bastante discretos, prevalecendo o uso de pequenas lápides ou placas normalmente alinhadas e padronizadas. $O$ espaço não apenas é planejado de forma a incorporar a vegetação, mas evidencia esse planejamento e o manejo de forma explícita. Assim, pode-se dizer que esse tipo engloba, além dos muitos espaços já chamados de cemitério-jardim, os lawn cemeteries (cemitérios gramados) dos Estados Unidos, sendo, junto aos cemitérios-parque, um dos tipos mais difundidos.

A associação de espaços fúnebres a jardins encontra-se no imaginário popular, remetendo a histórias sagradas e míticas. Michael Laurie (1983) afirma que muitas crenças religiosas descrevem o início dos tempos ou o término da vida em jardins paradisíacos. A própria definição da palavra em idiomas como o inglês, garden, remete ao mito do éden, o paraíso judaico-cristão ${ }^{15}$. Assim, em relação ao sentido do espaço, o cemitério-jardim é vinculado a um ideal de natureza mítica, evocado pela associação dos jardins a uma atmosfera repleta de paz e serenidade propícia ao repouso dos mortos (SANTOS, 2014).

Continuando a analisar distintas concepções do retorno à natureza associada à morte, outro cemitério verde que apresenta singularidades próprias para identificação de um tipo é o cemitério-bosque ou cemitério-floresta. Nesse tipo, os elementos dominantes são árvores de grande porte que se espalham pelo espaço de forma contínua, conformando uma espécie de bosque. As sepulturas estão distribuídas ao longo desse bosque, sob as copas das árvores, tendo seu tamanho regulado de modo a uniformizar a escala desses objetos. Esse recurso é adotado de modo a favorecer a noção da totalidade de marcos fúnebres, em contraposição ao destaque de aspectos e referências individuais. Esse ambiente, marcado pela conjunção entre túmulos e árvores, apresenta traços característicos da cultura nórdica, sendo usualmente encontrados em regiões como a Alemanha (Waldfriedhof) e Escandinávia (Skogskyrkogarden).

15 A etimologia de garden está associada aos termos hebraicos: gan, que significa proteger ou defender; e oden ou eden, que quer dizer prazer ou deleite (LAURIE, 1983)
O arquiteto paisagista Thorbjörn Andersson (1998) observa que, enquanto a tradição do sul da Europa vê a floresta como um lugar de banimento habitado por maus espíritos ${ }^{16}$, as culturas do norte europeu consideram a floresta o lar original do mundo humano. Andersson argumenta que, para a cultura nórdica, o paraíso não se encontra na concepção de um ambiente idílico, mas é representado pela imagem da floresta e de suas extensas áreas densamente vegetadas e arborizadas. Desse modo, o cemitério-bosque simboliza a noção de um retorno a uma natureza indomável, traduzida nas similaridades desses locais à imagem da floresta sob a ótica do norte europeu. De forma a potencializar essa perspectiva, o trajeto por esse tipo de espaço busca propiciar uma maior imersão e meditação em seus espaços. Essa percepção tem como base a ideia de que a representação dessa natureza indomável é capaz de estabelecer correspondências entre o interior da floresta e o eu interior, utilizando-se do percurso como uma espécie de peregrinação.

Na sequência, o último dos tipos de cemitério verde apontados é aquele que se sugere chamar cemitério ambiental. Em cronologia, ele é o mais recente desse grupo, sendo fruto direto do crescimento de uma consciência ecológica efetivada ao longo do século $X X$

O cemitério ambiental pode ser descrito como aqueles espaços que têm como base a realização de enterros naturais. Por sua vez, esses podem ser descritos como a prática de inumação na qual os corpos devem ser colocados na terra de maneira essencialmente ecológica, sem utilização de processos artificiais e procedimentos de tanatopraxia. No enterro natural, os cadáveres são colocados em recipientes biodegradáveis e as sinalizações usadas costumam ser pensadas de forma a serem absorvidas pelo ambiente circundante. Para os adeptos desse procedimento, a presença humana é vista como equivalente a qualquer outra forma de vida, animal ou vegetal, não devendo ser destacada de seu entorno. Ciente disso, Worpole (2003) aponta que o enterro natural refuta uma longa tradição pela qual os lugares dos mortos são objetos de arranjos visivelmente manipulados. Essa abordagem reflete um sig-

16 Cf. FUMAGALLI, Vito. Landscapes of Fear: Perceptions of Nature and the City in the Middle Ages. Cambridge: Polity, 1994 
nificativo distanciamento em relação a outros tipos de cemitério, principalmente os cemitérios-monumento, principal expoente de aspectos simbólicos decorrentes de temas como a família, classe social e religião.

De forma geral, no cemitério ambiental os atributos estéticos-simbólicos são colocados em segundo plano e o retorno à natureza é pensado de forma orgânica, um método para reduzir a pegada ecológica no planeta. Seu espaço é marcado pelo desejo de se estabelecer um movimento cíclico em relação à vida, mimetizando a morte ao ambiente. Dessa forma, a configuração desses locais se aproxima a muitos aspectos presentes nas chamadas áreas de preservação ambiental ${ }^{17}$. Em relação aos marcos fúnebres, os pontos de enterro tendem a se tornar inidentificáveis, portanto, para compreender o sentido desse espaço, é preciso ter em mente que o local específico de enterro não funciona como ponto focal da relação com o morto, mas a própria totalidade do ambiente toma para si a relação com a morte.

12 Em relação à sua denominação usual, é possível encontrar algumas variantes, sendo a mais comum o uso do termo natural burial grou$n d^{18}$. Em português, não há um termo de referência estabelecido, portanto, manteve-se a lógica de buscar vocábulos que levem em consideração tanto a caracterização como o sentido dos espaços. Com isso em mente, a opção pela palavra ambiental foi feita de forma a conjugar os dois significados principais.

Primeiramente, tendo como raiz o termo meio ambiente, a palavra ambiental pode ser associada a aspectos fundamentais da ecologia e da proteção do meio ambiente em si. Em segundo lugar, por meio do radical ambiente, ela também pode ser entendida como aquilo que é próprio a um ambiente, remetendo a conceitos essenciais do enterro natural como a assimilação do corpo ao ecossistema. Ainda em relação à denominação desse tipo, é importante pontuar que alguns cemitérios têm se baseado em princípios da ecologia, sendo usualmente chamados de cemitérios ecológicos. No entan-

$17 \mathrm{Em}$ alguns casos há, inclusive, o intuito de transformar efetivamente esses locais em reservas de preservação ambiental, após a finalização dos períodos de arrendamento fúnebre.

18 Em uma tradução simples para o português, seria o equivalente a algo como terreno de enterro natural. to, essas aplicações têm sido feitas sem alterar características de seus espaços tipológicos, ou seja, é possível haver outros tipos de cemitérios que possam ganhar a alcunha de ecológico, sendo necessário estabelecer a distinção. Já em relação ao uso da palavra natural, há que se levar em conta que, embora os tipos de espaços em questão tenham um aspecto que se assemelha a uma floresta nativa, eles costumam ser objeto tanto de organização paisagística como arquitetônica. Portanto, preteriu-se esse termo, optando-se por dissociar o processo de enterro natural, já consolidado, e a denominação espacial tipológica.

Finalmente, é preciso apontar que a maior parte desses locais tem surgido em lugares como o Reino Unido e o norte da Europa. No Brasil, por ora, esse tipo não encontra representantes estabelecidos. Ao menos no começo do século XXI, parte significativa da discussão sobre a transformação dos espaços fúnebres no Brasil tem seguido outro caminho.

A demanda por mais locais de enterro, principalmente nos grandes centros urbanos, tem dado algum destaque ao tema dos cemitérios verticais, próximo tipo a ser analisado. Todavia, antes de se aprofundar nesse tópico, é importante pontuar que, em termos de organização tipológica, a categorização de espaços fúnebres em cemitérios horizontais e verticais é bastante limitada. Esses termos acabam mais por indicar a predominância de uma ou outra forma de ocupação, mas em nada contribuem para a compreensão dos espaços em si. Ainda, eles costumam causar certa confusão, pois são chamados de cemitério vertical algumas construções verticalizadas de colocação de corpos ou restos mortais, mas que não conformam um espaço em si. No entanto, normalmente esses elementos cumprem a função de abrigar os corpos sem, necessariamente, conformar um espaço a ser frequentado. A utilização desses elementos, que podem ser chamados de estruturas fúnebres, é um recurso bastante comum, servindo como suporte à organização dos espaços fúnebres. Elas servem como elemento de composição e conformação de variados tipos de espaços fúnebres, podendo ser incorporadas e utilizadas junto a eles. Entre as estruturas fúnebres mais comuns encontram-se os ossários, columbários, cinerários e gavetas para colocação de cadáveres. 
Em relação aos espaços fúnebres conformados por ambientes construídos, ou seja, espaços onde as relações com a morte se desenvolvem em um local coberto, configurado por uma edificação, sugere-se a utilização do termo cemitério-edifício (ou cemitério edificado). Assim, o tipo cemitério-edifício pode ser configurado como uma ou mais edificações dotadas de infraestrutura construídas para abrigar cadáveres ou restos mortais, usualmente distribuídas em lóculos individuais. Nesses casos, é bastante comum o aproveitamento do espaço aéreo vertical para a disposição dos corpos.

Como apontado anteriormente, o debate a respeito desses espaços tem como base a busca por uma maior eficiência na ocupação dos espaços amparada no alto crescimento demográfico e na demanda por mais espaços de destinação dos corpos. Soluções de cemitério-edifício foram e têm sido desenvolvidas de diferentes formas e em diversos lugares, apresentando, assim, uma grande variedade de construções arquitetônicas que por si só podem representar diferentes tipologias edilícias. Ainda assim, ao passo que a opção por diferentes tratamentos do cadáver pode influir na configuração de cada edificação, as relações estabelecidas com a questão fúnebre nesses locais mantêm algumas semelhanças fundamentais, permitindo estabelecer uma aproximação entre seus sentidos. Enquanto a instituição de espaços fúnebres a céu aberto reforça uma noção de maior conexão com o natural (ou à ideia de natural), a escolha por um espaço edificado prioriza soluções construtivas e tecnológicas, tendo como base um dispositivo de maior compartimentação que é inerente à sua conformação. Portanto, mais do que uma resposta lógica a questões de organização logística-funcional, o cemitério-edifício carrega, em si, o próprio sentido da ação humana desempenhada não apenas no tratamento e na manipulação do corpo, mas na sua apresentação em um espaço propriamente abrigado e controlado.

Ainda tendo como objeto de discussão o crescimento populacional e a demanda por espaços fúnebres, cada vez mais têm sido apresentadas propostas baseadas no desenvolvimento de tecnologias que buscam estabelecer novos meios de se relacionar com a morte. Bastante limitadas ao campo das ideias, grande parte dessas pro- postas não foi, efetivamente, aplicada. Assim, como é de se esperar, nenhuma delas estabeleceu-se a ponto de se configurar como um tipo de espaço definido. De forma geral, nota-se que muitas delas parecem se aproximar à ideia de um cemitério difuso, onde a demarcação clara do lugar geográfico e da condição da matéria corporal perde importância em comparação aos tipos de espaços fúnebres aqui descritos. Ainda de forma incipiente, equipes de pesquisa têm elaborado estudos e modelos nos quais são desenvolvidos diferentes métodos de tratamento dos restos mortais. Nesses casos, prevalece o entendimento do corpo humano como uma matéria a ser transformada, podendo ter encaminhamentos diversos. Nesse caso, tanto o corpo-matéria transformada como o espaço de destinação acabam por pronunciar uma relação mais dinâmica e maleável, menos precisa. Resta aguardar para descobrir se algumas dessas propostas irão se consolidar e estabelecer, efetivamente, características próprias de um tipo de espaço fúnebre.

Por fim, ainda é importante pontuar alguns aspectos e temas deixados de lado por acreditar-se que precisam de maior tempo de maturação ou por terem menor relevância. No primeiro grupo é possível citar os chamados cemitérios virtuais que devem ganhar cada vez mais amplitude em um mundo onde a tecnologia avança rapidamente. Esse é um tema de enorme complexidade que vai, evidentemente, além da discussão sobre tipologias de espaços fúnebres, sendo capaz de provocar uma discussão que mexe com os próprios conceitos de espaço e de lugar. Já em relação ao segundo grupo, é possível citar o surgimento de categorias como cemitérios marítimos, cemitérios siderais e outros que parecem bastante insólitos. Por ora, pode-se dizer que esses têm um alcance bastante restrito, servindo mais como fonte de inspiração a uma discussão conceitual sobre as formas de relação com a morte do que com aspectos referentes à formação e composição de um espaço.

\section{Considerações Finais}

Em um cenário marcado pelo constante crescimento populacional e pela urbanização acentuada, cada vez mais os espaços fúnebres e cemitérios têm sido objeto de discussões que concernem à proble- 
mática urbana. Com isso em mente, este artigo empenhou-se em destacar a importância de se discutir esse tema de forma aprofundada, contribuindo para uma melhor compreensão da questão da morte e de seus espaços. Para tal, foram apresentadas distintas formas de entendimento sobre a identificação desses locais, de modo a embasar reflexões e proposições relacionadas à sua concepção e organização.

Ciente das subjetividades e da polissemia presente nessa discussão, é importante ressaltar que o intuito deste artigo não é buscar uma espécie de enciclopedização dos tipos de espaços fúnebres, mas suscitar um debate sobre seus sentidos tendo como foco principal o reconhecimento das características e das relações estabelecidas junto a eles. Sendo assim, as sugestões apresentadas não devem ser vistas como matéria absoluta ou definitiva, estando abertas a alterações e acréscimos conforme variação de sua conjuntura.

Muitos espaços fúnebres têm como principais parâmetros de planejamento e construção questões de ordem logística e utilitária.

14 Ao desenvolver seus tipos e características sob a ótica da arquitetura, da paisagem e do urbanismo, espera-se contribuir para um maior interesse por esses espaços também em aspectos como sua composição, qualificação e usufruto. Nessa perspectiva, é preciso destacar que os espaços fúnebres cemiteriais devem ser entendidos como espaços livres que, além da importância em relação a temas fúnebres como memória, luto e finitude, podem desempenhar papel relevante para a dinâmica urbana e ambiental do meio em que estão inseridos ${ }^{19}$.

Desse modo, ao apontar e analisar os tipos de espaços fúnebres, buscou-se contribuir para ampliar o alcance e a compreensão sobre o assunto, visto majoritariamente como um tabu na sociedade vigente devido à colocação da morte como tema interdito. Diante disso, é fundamental destacar aquilo que pode parecer inequívoco, mas nem sempre é percebido dessa maneira. Esses locais são carregados de aspectos culturais, afetivos e simbólicos, sendo a sua associação com a morte aquilo que define sua própria essência, sua razão de ser. Portanto, as reflexões trazidas têm como base justamente identificar e demarcar o protagonismo da questão fúnebre, 19 Para maior aprofundamento do tema sob essa perspectiva, cf. FUCHS, 2019, Parte III. dedicando-se a pensar como a morte se faz presente na percepção desses espaços.

\section{ReferênCias Bibliográficas}

ANDERSSON, Thorbjörn. The Functionalism of the Gardening Art. In Sweden: 20th- Century Architecture, ed. C. Caldeerly, J. Lindvall and W. Wang. Nova lorque, 1998.

ARIÈS, Philippe. O Homem diante da Morte. Trad. Luiza Ribeiro. São Paulo: Ed. Unesp, 2014

AUZELLE, Robert. Derniéres demeures: conception, composition, réalisation du cimetiére contemporain. Paris: Place du Panthéon, Mazarine, 1965

BRASIL, MINISTÉRIO DO MEIO AMBIENTE. Resolução CONAMA no 335 de 3 de abril de 2003 publicada no DOU no 101, de 28 de maio de 2003.

CAMPOS, Ana Paula Silva. Avaliação do potencial de poluição no solo e nas águas subterrâneas decorrente da atividade cemiterial. Dissertação de Mestrado em Saúde Ambiental, Faculdade de Saúde Pública, Universidade de São Paulo, São Paulo, 2007.

CATROGA, Fernando. O culto dos mortos como uma poética da ausência. In: ArtCultura, Uberlândia, v.12, n²0, p. 163-182, jan-jun 2010

COLÔMBIA. Resolución 5194 de 2010, Diario Oficial nº 47.925 de 16 de diciembre de 2010, Ministerio de la Protección Social, Bogotá

COMMISSION DES BIENS CULTURELS DU QUÉBEC (CBCQ). Évolution de la typologie des cimetières en Occident, 2004. Disponível em http://www.cpcq gouv.qc.ca/fileadmin/user_upload/docs/cimetieres.pdf. Acesso em 20 de set. 2020.

FUCHS, Felipe. Espaços de cemitério e a cidade de São Paulo. Dissertação de Mestrado em Paisagem e Ambiente, Faculdade de Arquitetura e Urbanismo, Universidade de São Paulo, São Paulo, 2019.

FUMAGALLI, Vito. Landscapes of Fear: Perceptions of Nature and the City in the Middle Ages. Cambridge: Polity, 1994.

HORNBOGEN, Marie-Luise. Heute Friedhof. Morgen Wohngebiet? Fallstudie Berlin zur Friedhofsentwicklung in der Stadtplanung. Master Thesis, Technische Universität Berlin, Berlim, 2016.

JACKSON, Kennet (autor), VERGARA, Camilo Jose (fotografias). Silent Cities: the Evolution of the American Cemetery. Princeton Architectural Press, 1989. LARRAMENDY S., GUTLEBEN C., LAILLE P. Paysages et entretien des cime-

tières - Recueil de ches repères et actions pour la réhabilitation écologique et paysagère des cimetières, Plant \& Cité. Angers, 2017.

LAURIE, Michael. Introducción a la arquitectura del paisaje. Barcelona: Gustavo Gili, 1983.

LE GOFF, Jacques. História e memória. Tradução Bernardo Leitão. Campinas: Editora da Unicamp, 1990.

MAGNOLI, Miranda. Espaço livre - objeto de trabalho. Revista Paisagem Ambiente: ensaios no 21. São Paulo, p. 175-197, 2006. 
NASCIMENTO, Cristiano Felipe Borba do. Nada vem do nada: por uma revisão contemporânea do conceito de tipo edilício. Revista do Programa de Pós-Graduação em Arquitetura e Urbanismo da FAUUSP n² 27, 2010.

QUATREMÈRE DE QUINCY, Antoine Chrysostome. Dictionnaire historique d'architecture - Volume 1. Librairie d'Adrien le Clere. Paris, 1832

REIS, João José. A morte é uma festa: ritos fúnebres e revolta popular no Brasil do século XIX. São Paulo: Companhia das Letras, 1991

SANTOS, Aline Silva. Morte e Paisagem: Os Jardins de Memória do Crematório Municipal de São Paulo. Tese de Mestrado, Universidade de São Paulo: São Paulo, 2015.

SCHUYLER, David. New Urban Landscape. USA: e Johns Hopkins University Press, 1986.

SIMÕES FERREIRA, José Manuel. Arquitectura para a Morte: a Questão Cemiterial e seus reflexos na Teoria da Arquitectura. Dissertação de Doutoramento em Teorias e História das Ideias, FCSH/UNL, 2005.

VOVELLE, Michel. Les attitudes devant la mort: problèmes de méthodes,

approches et lectures di érentes (note critique). In: Annales Économies,

Sociétés, Civilisations 31 année, n¹, p. 20-132, 1976. Disponível em: www. persee.fr/doc/ahess_0395-2649_1976_num_31_1_293702. Acesso em: 10 out. 2018.

WORPOLE, Ken. Last landscapes: the architecture of the cemetery in the West. Londres: Reaktion Books, 2003.
Felipe Fuchs

Universidade de São Paulo. Faculdade de Arquitetura e Urbanismo Rua do Lago, 876 - Butantã, São Paulo, SP, Brasil.

Orcid: 0000-0002-6139-6366

fuchsfelipe@hotmail.com

Nota do Editor

Recebido em: 07/04/2021

Aprovado em: 09/06/202

Revisão: RMO 